\title{
PERFORMANCE ANALYSIS AND TESTS ON THE KAERI DEVISED SPACER GRIDS FOR PWRS
}

\author{
Kee-nam Song \\ Korea Atomic Energy Research Institute \\ knsong@kaeri.re.kr
}

\author{
Kyung-ho Yoon ${ }^{1)}$, Jae-yong Kim ${ }^{2}$, \\ Tae-hyun Chun ${ }^{3)}$, Kang-hee Lee ${ }^{4)}$ \\ Korea Atomic Energy Research Institute \\ ${ }^{1)}$ khyoon@kaeri.re.kr \\ 3) thchun@kaeri.re.kr \\ 2)kjykjy@kaeri.re.kr \\ 4) leekh@kaeri.re.kr
}

\section{INTRODUCTION}

In Pressurized light Water Reactor (PWR) fuel assemblies, a spacer grid is one of the core components for laterally and vertically supporting the nuclear fuel rods. Therefore, a spacer grid has been continuously developed since 1970 to improve its performance. Based on the mechanical/structural and thermo hydraulic design experiences and by scrutinizing the design features of foreign advanced nuclear fuels and foreign patents of spacer grids, KAERI has devised 18 kinds of spacer grid shapes and has applied for domestic and foreign patents since 1997. To date, KAERI has obtained US, Japan, China and Republic Of Korea (ROK) patents for 16 kinds of spacer grid shapes from them and the others are under review for patent-rights in the USA, EC, China, and ROK. Screening test and analysis was carried out to establish and to prioritize the performance features of the KAERI devised spacer grid shapes. Throughout the screening test and analysis, five spacer grid shapes were selected. Finally, two new spacer grid shapes were determined by combining the main features of the five spacer grid shapes in order to maximize their performance. Mechanical/structural and thermo hydraulic performance evaluations of the new spacer grid shapes and of two commercial spacer grids have been carried in detail out through tests and analyses. And also a performance evaluation of two commercial spacer grid shapes was carried out for the sake of a comparison. The performance evaluation results included the spring characteristics, fuel rod vibration characteristics, fretting wear resistance, the impact strength characteristics, CHF enhancement, and the pressure drop of the spacer grids.

\section{FRETTING WEAR AND CHF TEST RESULTS}

The fretting wear resistance test under a high temperature and high pressure condition was performed at AECL of Canada in early 2004. The AECL wear resistance test at a reactor operation temperature to derive the fuel rod wear coefficient for the PWR fuel rod/the Opt. $\mathrm{H}$ spacer grid (Yoon, 2004) was performed by using a sliding and impact wear tester. Table 1 shows the AECL wear test results of the
Opt. H and Ref. B spacer grid springs. According to Table 1, the wear resistance of the Opt. $\mathrm{H}$ spacer grid spring is superior to that of the Ref. B spacer grid spring, i.e. smaller wear coefficients $(\mathrm{K})$ and also smaller maximum wear depths when compared to the Ref. B spacer grid spring.

Table 1 AECL results at spring (based on the Opt. H's value)

\begin{tabular}{|l|c|c|}
\hline & Opt. H & Ref. B \\
\hline Mean FR wear coefficient (K) & 1.00 & 4.39 \\
\hline Max. FR wear mark depth & 1.00 & 2.44 \\
\hline
\end{tabular}

The critical heat flux (CHF) Freon test for the Opt. H spacer grid with the Hybrid flow mixing devices was performed at KAERI. The test results show that the CHF performance for Opt. $\mathrm{H}$ spacer grid is enhanced by up to $16.4 \%$ when compared to the spacer grid without a mixing vane (Shin, 2006). It is known that the CHF performance for the Ref. B spacer grid with a split type mixing vane was enhanced by up to $12.5 \%$ when compared with the spacer grid without a mixing vane.

\section{CONCLUSIONS}

The mechanical/structural and thermo hydraulic performance evaluations for two new spacer grid shapes designed by KAERI were carried out. Also the same evaluation for two commercial spacer grid shapes was carried out as well. The results of the comparisons show that the performances of the new spacer grid shapes are superior or comparable to those of the commercial spacer grid shapes from the aspects of the spring characteristics, fretting wear resistance, fuel rod vibration characteristics, CHF enhancement, and a pressure drop of the spacer grids. And also the Opt. $\mathrm{H}$ spacer grid could meet the $0.3 \mathrm{~g}$ seismic criteria for both the 16x 16 type and 17x17 type spacer grid.

\section{REFERENCES}

Yoon K. H., et al., 2004, US Patent US 6707872 B2.

Shin C. H., et al., 2006, Proceedings of KNS Spring Meeting. 
ICONE15-10125

\title{
PERFORMANCE ANALYSES AND TESTS ON THE KAERI DEVISED SPACER GRIDS FOR PWRS
}

\author{
Kee-nam Song \\ Korea Atomic Energy Research Institute \\ Kyung-ho Yoon \\ KAERI \\ P.O.BOX 105 Yusong, Daejon, KOREA \\ Phone:82-42-868-2254, Fax: 82-42-863-0565 \\ knsong@kaeri.re.kr \\ Tae-hyun Chun
KAERI \\ Kang-hee Lee \\ KAERI
}

\author{
Jae-yong KIm \\ KAERI
}

Keywords: Spacer Grid Spring, KAERI Devised Spacer Grid, Nuclear Fuel Rod, PWR, Fretting Wear

\begin{abstract}
Spacer grid which is one of the most important structural components in a pressurized light water reactor fuel assembly supports the fuel rods laterally and vertically. Based on design experiences and by scrutinizing the design features of foreign advanced nuclear fuels and the foreign patents of spacer grids, KAERI has devised its own spacer grid shapes and has acquired patents. In this study, a performance evaluation of two new spacer grid shapes devised by KAERI was carried out from the mechanical/structural and thermo hydraulic view points. And also performance evaluation of two commercial spacer grid shapes was carried out for the sake of a comparison. The comparisons included the spring characteristics, fuel rod vibration characteristics, fretting wear resistance, impact strength characteristics, CHF enhancement, and the pressure drop of the spacer grid shapes. The comparison results have shown that the performances of the new spacer grid shapes are better or at least not worse than those of the commercial spacer grid shapes.
\end{abstract}

\section{INTRODUCTION}

In Pressurized light Water Reactor (PWR) fuel assemblies as shown in Fig. 1, a spacer grid is one of the core components for laterally and vertically supporting the nuclear fuel rods. Therefore, a spacer grid has been continuously developed since 1970 to improve its performance.

Based on the mechanical/structural and thermo hydraulic design experiences and by scrutinizing the design features of foreign advanced nuclear fuels and foreign patents of spacer grids, KAERI has devised 18 kinds of spacer grid shapes and has applied for domestic and foreign patents since 1997. To date, KAERI has obtained US, Japan, China and Republic Of Korea (ROK) patents for 16 kinds of spacer grid shapes from them and the others are under review for patent-rights in the USA, EC, China, and ROK.

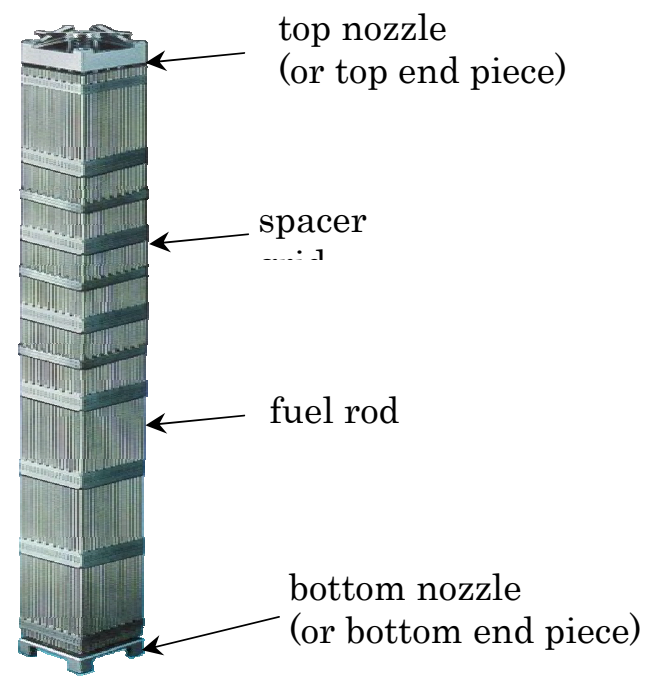

Fig. 1 PWR fuel assembly 
Screening test and analysis was carried out to establish and to prioritize the performance features of the KAERI devised spacer grid shapes. Throughout the screening test and analysis, five spacer grid shapes were selected. Finally, two new spacer grid shapes were determined by combining the main features of the five spacer grid shapes in order to maximize their performance. Mechanical/structural and thermo hydraulic performance evaluations of the new spacer grid shapes and of two commercial spacer grids have been carried in detail out through tests and analyses. And also a performance evaluation of two commercial spacer grid shapes was carried out for the sake of a comparison. The performance evaluation results included the spring characteristics, fuel rod vibration characteristics, fretting wear resistance, the impact strength characteristics, CHF enhancement, and the pressure drop of the spacer grids.

\section{FUNCTIONS OF SPACER GRIDS}

General roles of the spacer grid assembly are: (1) providing lateral and vertical support for fuel rods (2) maintaining a fuel rod space under accidental and operational loading conditions (3) promoting a mixing of the coolant (4) keeping the guide tubes straight so as not to impede a control rod insertion under any normal or accidental conditions.

The spacer grid which supports nuclear fuel rods laterally and vertically with a friction grip is an interconnected array of slotted grid straps welded at the intersections and it is crossed to form an egg-crate like structure shown in Fig. 2. Each cell in the spacer grid employs a fuel rod support system consisting of two orthogonal sets of two dimples and a spring. They contact with the fuel rods and absorb any vibration impacts during a loading process of the fuel rods into the spacer grid, shipping and handling of the fuel assemblies, and a reactor operation, itself. The support system not only allows the fuel rod to move through the cell axially as necessary for thermal and rod growth movements, but also it follows any fuel rod diametric changes during an operation while maintaining an alignment.

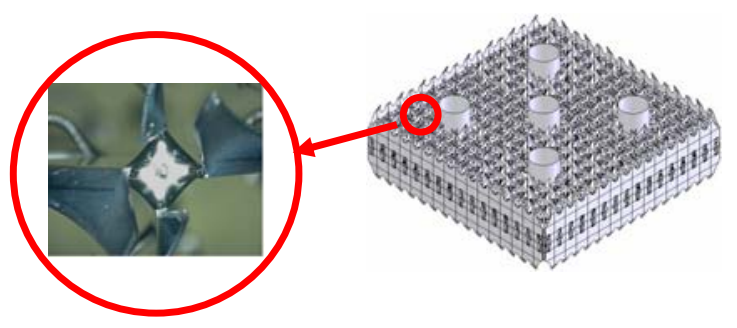

Fig. 2 Spacer grid and mixing vanes

During an operation in a nuclear reactor, the grid springs are exposed to an intensive irradiation that causes the grid springs to lose their initial spring force against the fuel rods, up to over $90 \%$ of the initial spring force, especially up to $100 \%$ for a Zircaloy spacer grid (Billerey, 2004). Thus, losing the initial spring force causes the fuel rods to excessively vibrate and chatter against the spring and dimples and consequently could lead to fretting wear damage of the fuel rods as shown in Fig. 3. To reduce the excessive lose of the initial spring force, an improvement of the spring structure and shape is required in the direction of extending the elastic limit and reducing the plastic set when the fuel rods are inserted. In addition, the contact shape between the spring and the fuel rod must also be considered to reduce the fretting wear damage and to provide a stable fuel rod support. The characteristics of the springs and dimples are very important to support the fuel rods throughout the residence time of a fuel in the reactor.

Mixing vanes are attached to the grid spacers as shown in Fig. 2 to increase the thermal performance by promoting a turbulent level, increasing a mixing between the subchannels, inducing a swirl flow and so on. Hybrid flow-mixing devices designed by KAERI are composed of two types of vanes, called a primary vane and a secondary vane. The hybrid flow-mixing device has been registered for patents in US, Japan, and ROK (Chun, 2005; Chun, 2003; Chun, 2004). The primary vane set is primarily for the generation of a cross flow between channels. Meanwhile, the secondary vane set is primarily for a swirl flow generation within channels.

Another function of the spacer grid is to protect the fuel rods from external impact loads in an abnormal operating environment such as an earthquake or a Loss-Of-Coolant Accident (LOCA) and to maintain the guide tubes (or fuel skeleton structure) straight so as not to impede a control rod insertion under any normal or abnormal conditions. Moreover, the spacer grid must maintain the instrumentation tube straight so that a plant's neutronic instrumentation can be freely inserted and removed from the tube even after a design's lateral loading conditions. Therefore a plastic deformation of the spacer grid needs to be limited and it must be designed to have enough impact lateral strength.

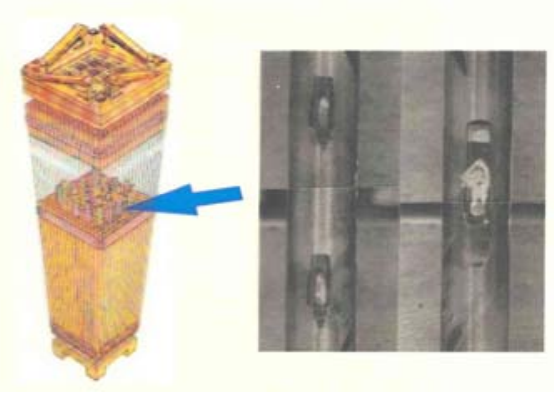

Fig.3 Fuel rod wear scar

\section{SPACER GRID SHAPES FOR PERFORMANCE EVALUATION}

The performance evaluation of two new spacer grids was performed in detail. One of the new spacer grid shapes is a spacer grid with an optimized H-shape spring (Yoon, 2004) as shown in Fig. 4. Based on the H-shape spring (Yoon, 2000) of which the main feature is a conformal contact shape at the support part of the fuel rods, the optimized for $\mathrm{H}$-shape spring was optimized its shape to enhance the fuel rod support characteristics. The H-shape spring with a conformal contact shape (or contoured spring shape) was first issued by a KAERI designer in 1997 (Yoon, 2000). In order to enhance the support performance of the H-shape spring, a systematic optimal design was applied to obtain an 
optimized shape of the spring including the contact contour (Song, 2002). The other is the Doublet-type spacer grid (Kang, 2004). This spacer grid is also modified based on the initial Doublet-type spacer grid (Kang, 2000) of which the main feature is a support of a fuel rod with a line contact.
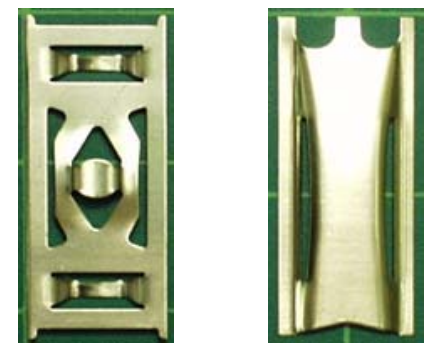

Fig. 4 New spacer grid springs (Left: Opt. H; Right: Double)

Two commercial spacer grid shapes were selected as references for the sake of comparisons for the performance evaluation. One is widely used in the current commercial fuel assembly, which is designated in this paper as Ref. A. The other is a cutting-edge spacer grid designated as Ref. B, whose shape of the supporting parts is similar to that of the KAERI spacer grid with an Opt. H spring.

\section{PERFORMANCE EVALUATION}

\subsection{Spring Characteristics}

Force-deflection tests of four kinds of spacer grid springs were performed up to the plastic range. The tests were performed on a spring specimen as shown in Fig. 4 and in a test machine as shown in Fig. 5.

Plastic sets when the springs are deflected up to $1.0 \mathrm{~mm}$ and unloaded are shown in Table 1. From the point of view of a fuel rod support, soft springs are preferable; therefore we recommend that the stiffness of a spring be 100 250 $\mathrm{N} / \mathrm{mm}$. According to Table 1, the stiffness of the new spacer grid springs are within the recommended stiffness range while that of Ref. A is not within the range. In addition, we found the elastic range to be larger and the plastic set to be less for the new spacer grid springs when compared to those of the commercial springs as shown in Table 1.

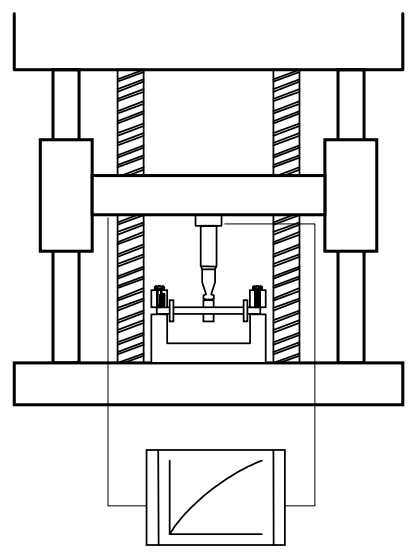

Fig. 5 Spring characteristic test machine
Table 1 Ratio of the plastic set for each spring

\begin{tabular}{|c|c|c|}
\hline Spring shape & $\begin{array}{c}\text { Elastic } \\
\text { Stiffness } \\
(\mathrm{N} / \mathrm{mm})\end{array}$ & Plastic set* $^{*}$ \\
\hline Doublet (new 1) & 114 & 1.255 \\
Opt. H (new 2) & 233 & 1.000 \\
Ref. A & 708 & 1.984 \\
Ref. B & 210 & 1.551 \\
\hline
\end{tabular}

* Ratio based on the value of Opt. $\mathrm{H}$

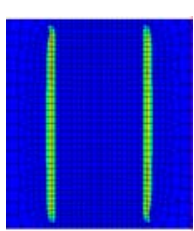

Ref. B

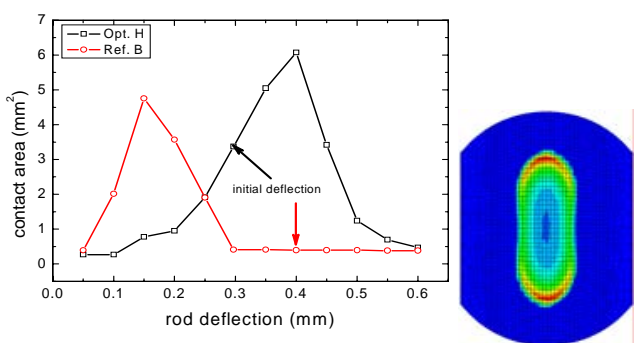

Contact area vs. spring deflection Opt. $\mathrm{H}$
Fig. 6 Contact area vs. spring deflection and contact area at an initial deflection for each spring

\subsection{Fuel Rod Vibration Characteristics}

Since a fuel rod is supported by several spacer grids, modal parameters of a fuel rod such as the natural frequencies and mode shapes are closely related to a spacer grid's characteristics. To investigate the fuel rod support and vibration characteristics, a modal test of a single dummy fuel rod supported by five spacer grids has been performed not only to obtain the natural frequencies and mode shapes of the rod but also to establish the spacer grid effects on the vibration characteristics of the rod in the test set-up as shown in Fig. 7. The objective of this test is to compare the maximum deflection of each spacer grid shape when the same input force is applied to the fuel rod. The responses from the accelerometers at a quarter and three quarters for each span and a laser vibrometer at the middle of the third span are obtained and analyzed. Three kinds of input forces of $0.5,0.75$, and $1.0 \mathrm{~N}$ were used in the test. Fig. 8 shows the test result for an input force of $0.75 \mathrm{~N}$. According to Fig. 8 the maximum deflection for the springs are as follows; for the Doublet spring $0.04 \mathrm{~mm}$, for the Opt. H spring $0.14 \mathrm{~mm}$, and for Ref. B $0.16 \mathrm{~mm}$. Similar tendencies were obtained for the other input forces. When the maximum deflections are smaller, it means that the spacer grid has a better vibration resistance to external forces and this leads to a greater resistance to fretting wear damage. From the results we can draw a conclusion that the vibration characteristics for resisting a fretting wear for the new spacer grid shapes are superior to that of the Ref. B spacer grid shape. This conclusion will be confirmed from the fretting wear characteristics of this paper. 


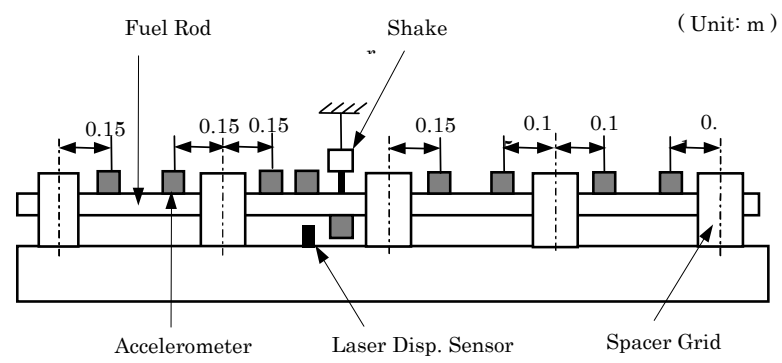

Fig. $\quad 7$ Test set-up for the fuel rod vibration test

\subsection{Fretting Wear Characteristics}

The fretting wear resistance test under a high temperature and high pressure condition was performed at AECL of Canada in early 2004. The AECL wear resistance test at a reactor operation temperature to derive the fuel rod wear coefficient for the PWR fuel rod/the Opt. H spacer grid was performed by using a sliding and impact wear tester. Table 2 shows the AECL wear test results of the Opt. $\mathrm{H}$ and Ref. B spacer grid springs. According to Table 2, the wear resistance of the Opt. $\mathrm{H}$ spacer grid spring is superior to that of the Ref. B spacer grid spring, i.e. smaller wear coefficients $(\mathrm{K})$ and also smaller maximum wear depths when compared to the Ref. B spacer grid spring.

Table 2 AECL results at spring (based on the Opt. H’s value)

\begin{tabular}{|l|c|c|}
\hline & Opt. H & Ref. B \\
\hline Mean FR wear coefficient (K) & 1.00 & 4.39 \\
\hline Max. FR wear mark depth & 1.00 & 2.44 \\
\hline
\end{tabular}

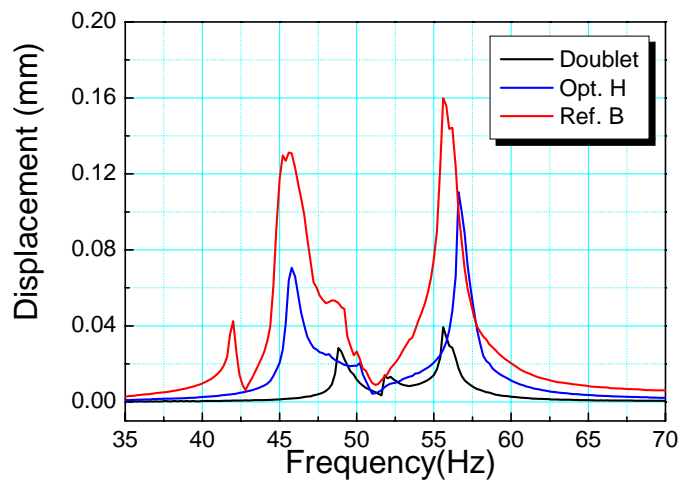

Fig. 8 Fuel rod deflection vs. frequency

\subsection{CHF Enhancement}

The critical heat flux (CHF) Freon test for the Opt. H spacer grid with the Hybrid flow mixing devices was performed at KAERI. The test results as shown in Fig. 9 show that the CHF performance for Opt. H spacer grid is enhanced by up to $16.4 \%$ when compared to the spacer grid without a mixing vane (Shin, 2006). It is known that the CHF performance for the Ref. B spacer grid with a split type mixing vane was enhanced by up to $12.5 \%$ when compared with the spacer grid without a mixing vane (Shin, 2006).

\subsection{Spacer Grid Buckling Strength}

The buckling strength test was performed by using a pendulum type impact tester as shown in Fig. 10 for the Opt.
$\mathrm{H}$ spacer grid and Ref. B spacer grid. And also a finite element analysis on the buckling strength of the spacer grid assemblies was performed. Table 3 shows the test and analysis results. The impact strength of the Opt. H spacer grid is known to be a little lower than that of the Ref. B spacer grid from the test and analysis. So, in order to enhance the impact strength of the Opt. $\mathrm{H}$ spacer grid, the size and location of the dimples were modified recently by using a systematic optimal design technique. The impact strength of the modified Opt. H spacer grid increased by up to $5.6 \%$ compared with that of the Opt. $\mathrm{H}$ spacer grid in Table 3. According to Table 3, the Opt. H spacer grid could meet the $0.3 \mathrm{~g}$ seismic criteria for both $16 \mathrm{x} 16$ type and 17x17 type spacer grid (Song, 2006).

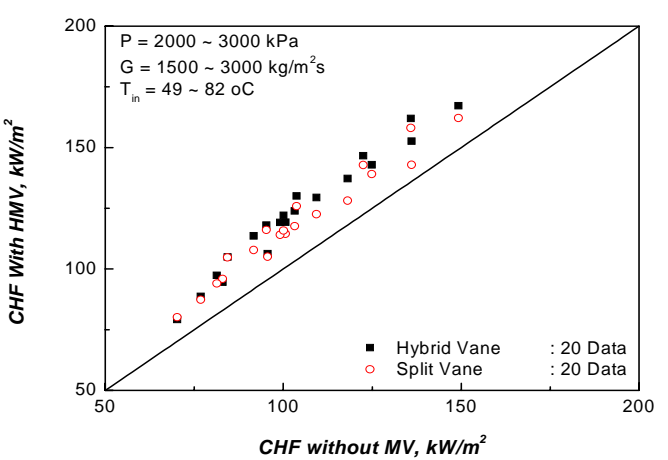

Fig. 9 CHF enhancements

Table 3 Spacer grid buckling strength under Room Temperature

\begin{tabular}{|l|l|c|c|c|}
\hline \multicolumn{2}{|c|}{} & \multicolumn{3}{|c|}{ Buckling strength (kN) } \\
\cline { 3 - 5 } \multicolumn{2}{|c|}{} & $\begin{array}{c}\text { Analysis } \\
\text { (A) }\end{array}$ & $\begin{array}{c}\text { Test } \\
\text { (B) }\end{array}$ & $\begin{array}{c}\text { Ratio } \\
\text { (A/B) }\end{array}$ \\
\hline \multirow{2}{*}{$\begin{array}{l}\text { 16x16 } \\
\text { type }\end{array}$} & Opt. H & 23.5 & 25.5 & 0.922 \\
\cline { 2 - 5 } $\begin{array}{l}\text { 17x17 } \\
\text { type }\end{array}$ & Opt. B & 25.7 & 27.7 & 0.928 \\
\cline { 2 - 5 } & Opt-Opt. H & 28.2 & $30.6^{*}$ & 0.92 \\
\hline
\end{tabular}

* estimated value using conversion factor $1 / 0.92$

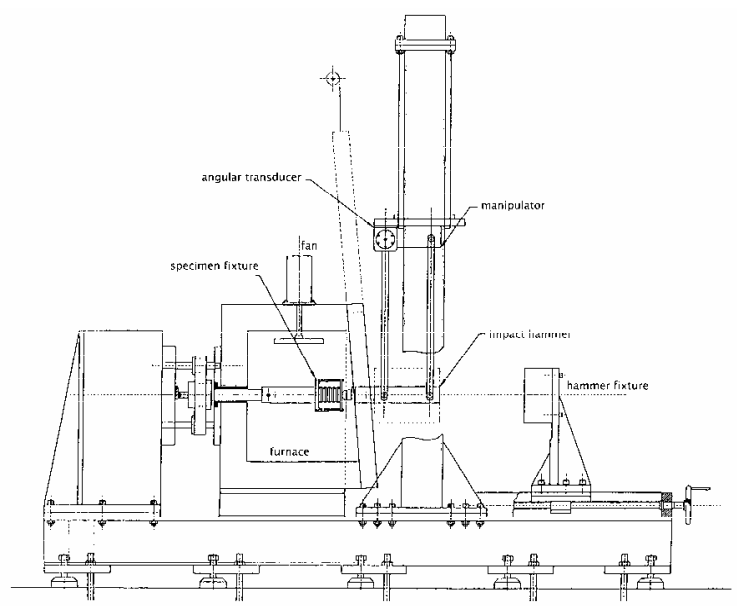

Fig. 10 Impact strength tester 
According to Table 3, the buckling strength of the $17 \mathrm{x} 17$ type spacer grid is by far higher than that of the $16 \times 16$ type spacer grid for the Opt. $\mathrm{H}$ spacer grid. Two reasons are probable for this. First, the number of straps is higher for the $17 x 17$ type spacer grid than for the $16 \times 16$ type spacer grid. Second, the location and size of the guide thimbles are smaller for the $17 x 17$ type spacer grid than those for the 16x16 type spacer grid as shown in Fig. 11. The larger the size of the guide thimble is, the lower the impact strength of the spacer grid is.

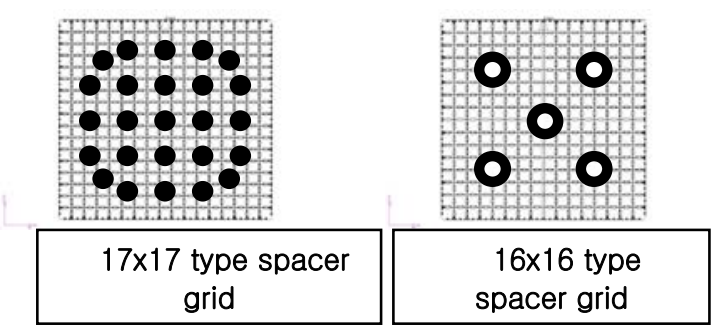

Fig. 11 Spacer grid cross-section for the 17x17type and 16x16 type spacer grid

\subsection{Pressure Drop}

The pressure drop test for the Opt. H spacer grid with the Hybrid flow mixing devices was performed at KAERI. According to the pressure drop test results (Oh, 2006) the pressure drop for the Opt. $\mathrm{H}$ spacer grid is lower by up to $7 \%$ than that for the Ref. B spacer grid with the split type mixing vane.

\section{CONCLUSIONS}

The mechanical/structural and thermo hydraulic performance evaluations for two new spacer grid shapes designed by KAERI were carried out. Also the same evaluation for two commercial spacer grid shapes was carried out as well. The results of the comparisons show that the performances of the new spacer grid shapes are superior or comparable to those of the commercial spacer grid shapes from the aspects of the spring characteristics, fretting wear resistance, fuel rod vibration characteristics, CHF enhancement, and a pressure drop of the spacer grids. And also the Opt. $\mathrm{H}$ spacer grid could meet the $0.3 \mathrm{~g}$ seismic criteria for both the 16x 16 type and 17x17 type spacer grid.

\section{ACKNOWLEDGEMENTS}

This project has been carried out under the nuclear R \& D program by MOST (Ministry $\underline{\text { Of }}$ Science and Technology in Republic of Korea).

\section{REFERENCES}

Billerey A., 2004, IAEA TCM on Fuel Assembly Structural Behavior.

Chun T. H., et al., 2005, US Patent 6,845,138 B2.

Chun T. H., et al., 2003, Japan Patent 3463998, 2003.

Chun T. H., et al., 2004, ROK Patent 0423738, 2004.
Yoon K. H., et al., 2004, US Patent US 6707872 B2.

Yoon K. H., et al, 2000, US Patent US 6167105.

Song K. N, et al., 2002, ICONE11-36500.

Kang H. S., et al., 2004, US Patent US 6744843 B2.

Kang H. S. et al., 2000, US Patent US 6130927.

Shin C. H., et al., 2006, Proceedings of KNS Spring Meeting.

Song K. N., et al., 2006, Proceedings of KNS Spring Meeting.

Oh D. S., et al., 2006, KAERI/TR-3223/2006. 